\title{
Radiative transfer simulations for the MADRAS imager of Megha-Tropiques
}

\author{
K SRinivasa Ramanujam and C Balaji* \\ Department of Mechanical Engineering, Indian Institute of Technology Madras, Chennai 600 036, India. \\ *e-mail: balaji@iitm.ac.in
}

This paper reports the radiative transfer simulations for the passive microwave radiometer onboard the proposed Indian climate research satellite Megha-Tropiques due to be launched in 2011. These simulations have been performed by employing an in-house polarized radiative transfer code for raining systems ranging from depression and tropical cyclones to the Indian monsoon. For the sake of validation and completeness, simulations have also been done for the Tropical Rainfall Measuring Mission (TRMM)'s Microwave Imager (TMI) of the highly successful TRMM mission of NASA and JAXA. The paper is essentially divided into two parts: (a) Radiometer response with specific focus on high frequency channels in both the radiometers is discussed in detail with a parametric study of the effect of four hydrometeors (cloud liquid water, cloud ice, precipitating water and precipitating ice) on the brightness temperatures. The results are compared with TMI measurements wherever possible. (b) Development of a neural network-based fast radiative transfer model is elucidated here. The goal is to speed up the computational time involved in the simulation of brightness temperatures, necessitated by the need for quick and online retrieval strategies. The neural network model uses hydrometeor profiles as inputs and simulates spectral microwave brightness temperature at multiple frequencies as output. A huge database is generated by executing the in-house radiative transfer code for seven different cyclones occurred in North Indian Ocean region during the period 2001-2006. A part of the dataset is used to train the network while the remainder is used for testing purposes. For the purpose of testing, a typical scene from the southwest monsoon rain is also considered. The results obtained are very encouraging and show that the neural network is able to mimic the underlying physics of the radiative transfer simulations with a correlation coefficient of over $99 \%$.

\section{Nomenclature}

$a, b, \alpha, \gamma:$ constants appearing in modified gamma distribution for hydrometeors

$B \quad$ : Planck blackbody function, W/ $\left(\mathrm{m}^{2} \mu \mathrm{m} \mathrm{sr}\right)$

CI : cloud ice, $\mathrm{g} / \mathrm{m}^{3}$

CLW : cloud liquid water, $\mathrm{g} / \mathrm{m}^{3}$

$\mathrm{H} \quad$ : horizontal polarization

$I, Q, U, V:$ Stokes parameters

$P \quad$ : scattering (or Mueller) matrix

$P I \quad$ : precipitating ice, $\mathrm{g} / \mathrm{m}^{3}$
$P w$ : precipitating water, $\mathrm{g} / \mathrm{m}^{3}$

$R_{\mathrm{r}}$ : ground or surface rain rate, $\mathrm{mm} / \mathrm{h}$

$V$ : vertical polarization

Greek Symbols

$\theta$ : zenith angle

$\mu$ : cosine of the zenith angle

$\tau$ : optical depth

$\phi$ : azimuthal angle

$\tilde{\omega}$ : single scattering Albedo

Keywords. Radiative transfer; artificial neural network; Megha-Tropiques; TRMM mission; inverse problem. 


\section{Introduction}

One of the important areas of application of the remote sensing of the earth's atmosphere is the retrieval of useful rainfall products such as instantaneous surface rain rate and the vertical distribution of hydrometeors. The first step in developing an algorithm for such retrieval problems is to model the radiative heat transfer emerging from the surface of the earth and passing through the raining atmosphere. The latter emits, absorbs and/or scatters, and hence is participatory in nature. In view of the existence of rain particles in multi-phase, the sensors aboard the satellites are equipped to handle multiple frequencies based on their sensitivity to a particular phase. For example, the Tropical Rainfall Measuring Mission (TRMM) satellite that was jointly launched by National Aeronautics and Space Administration (NASA) and the Japanese Aerospace Exploration Agency (JAXA) in 1997, has a passive microwave radiometer on board, that scans the earth's surface at five different frequencies, namely, 10.65, 19.35, 21.3, 37 and $85.5 \mathrm{GHz}$ (Kummerow et al 1998). The 10.65, 19.35 and $21.3 \mathrm{GHz}$ are termed low frequency channels and are sensitive to emission and absorption from cloud liquid water and liquid rain particles. The $37 \mathrm{GHz}$ channel shows sensitivity to emission from liquid water at low rain rates, and scattering from ice at higher rain rates. The high frequency channels, typically above $85 \mathrm{GHz}$, are largely sensitive to scattering from ice particles. The Megha-Tropiques satellite (Srinivasan and Narayanan 2003) - a joint venture between Indian Space Research Organisation (ISRO) and Centre National d'Études Spatiales (CNES) from France - is scheduled to be launched early next year. This will be India's first climate research satellite. The microwave radiometer aboard the MeghaTropiques satellite christened Microwave Analysis and Detection of Rain and Atmospheric Structures (MADRAS) is proposed to have channels that are similar to TRMM, sans the $10.65 \mathrm{GHz}$ in lieu of which a high frequency $157 \mathrm{GHz}$ scattering channel is added. Table 1 shows the channels of MADRAS and their related mission objectives (reproduced from Megha-Tropiques satellite sensor characteristics report, ISRO, July 2006, see Pal et al 2007).

It has been shown by various authors that the presence of rain and ice droplets in the atmosphere, in general, tends to polarize the electromagnetic waves propagating through it (see Czekala 1997; Roberti and Kummerow 1999; Troitsky et al 2003). Hence, any radiative transfer model developed to simulate the top of atmosphere radiances (also known as brightness temperatures), should also take care of the effect of polarization from the rain particles.

Water in the atmosphere exists in multiple phases depending on the prevailing temperature and pressure of the surroundings. Moist air from the ocean surface rises above due to the convective motion of air to greater altitudes. Since the temperature of the atmosphere decreases with an increase in altitude, the moist air condenses and forms a suspension of liquid droplets. These cloud droplets evolve by growing in size due to agglomeration and become precipitating water under the action of earth's gravity. The non-precipitating water droplets are pushed up by the continuous upward motion of the moist air from the oceanic surface beyond $0^{\circ} \mathrm{C}$, which will result in ice deposition. The continuous agglomeration of cloud ice results in the formation of precipitating ice or ice that is about to precipitate. The rate of liquid rainfall at the ground surface depends on the precipitating water content near the earth's surface and the droplet size. The atmospheric parameters related to precipitation such as cloud liquid water (CLW), precipitating water (PW), cloud ice $(\mathrm{CI})$ and precipitating ice (PI) are collectively known as hydrometeors. These four rain parameters are employed in the present study. Figure 1(a) and (b) show a typical vertical hydrometeor profile for low rain $(\sim 1 \mathrm{~mm} / \mathrm{h})$ and high rain $(\sim 25 \mathrm{~mm} / \mathrm{h})$.

Table 1. Channels of MADRAS and their related mission objectives.

\begin{tabular}{lccl}
\hline $\begin{array}{l}\text { Frequency } \\
(\mathrm{GHz})\end{array}$ & Polarization & $\begin{array}{c}\text { Pixel size } \\
(\mathrm{km})\end{array}$ & Mission \\
\hline 18.7 & $\mathrm{H}+\mathrm{V}$ & $\leq 40$ & Rain above oceans \\
23.8 & $\mathrm{~V}$ & $\leq 40$ & Integrated water vapour \\
36.5 & $\mathrm{H}+\mathrm{V}$ & $\leq 40$ & $\begin{array}{c}\text { Liquid water in clouds, } \\
\text { rain above sea }\end{array}$ \\
89 & $\mathrm{H}+\mathrm{V}$ & $\leq 10$ & $\begin{array}{c}\text { Convective rain areas } \\
\text { over land and sea }\end{array}$ \\
& $\mathrm{H}+\mathrm{V}$ & $\leq 6$ & Ice at cloud tops \\
\hline
\end{tabular}



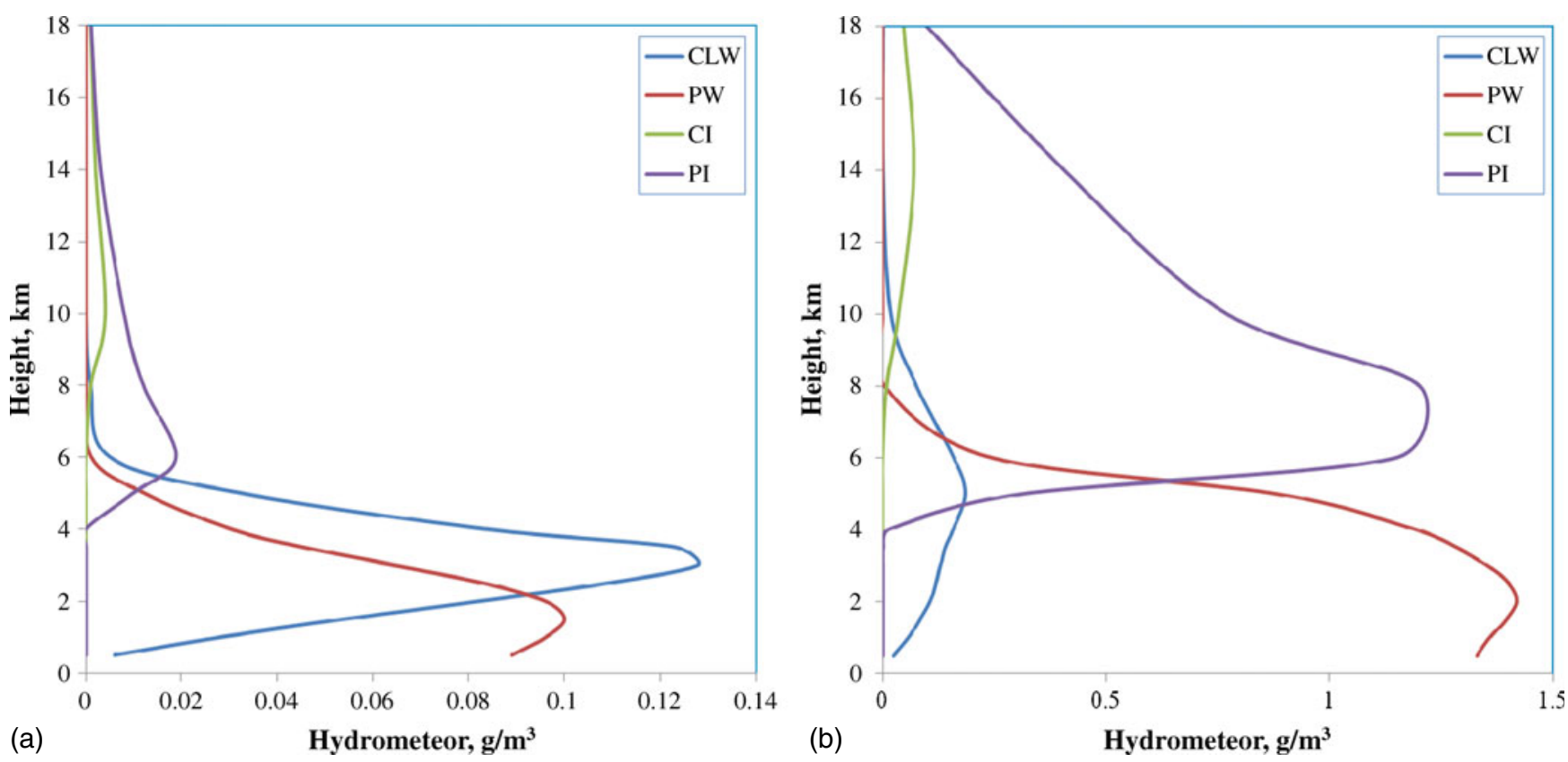

Figure 1. Typical vertical hydrometeor profile for (a) low rain and (b) high rain.

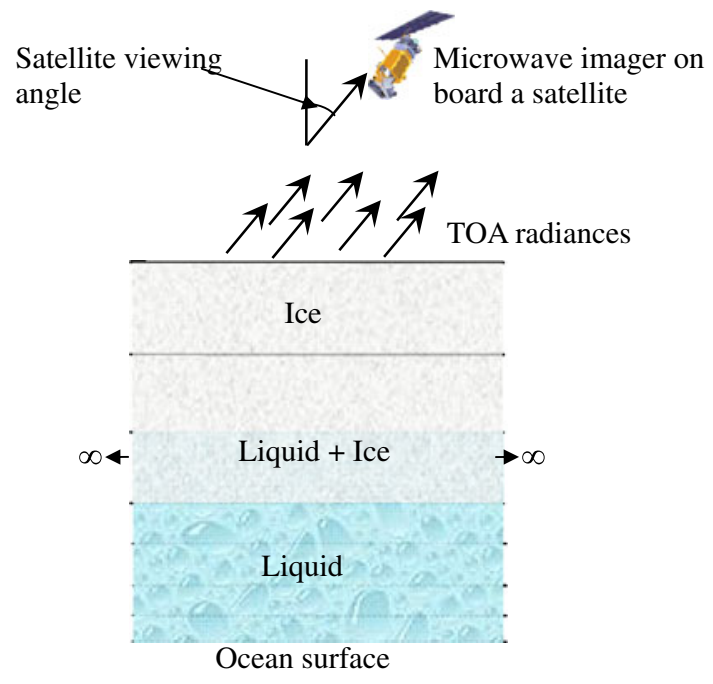

Figure 2. Schematic of a layered raining atmosphere.

In this study, the atmosphere is considered as a plane parallel medium and is divided into 14 layers; the bottommost layer represents the oceanic background that is modeled as a specular surface, while the topmost layer represents the top-of-atmosphere (TOA) radiance. Figure 2 shows a schematic of the earth's surface and the multi-layer atmosphere considered in the present work.

As a first step in solving the radiative transfer equation, the atmospheric and the oceanic parameters are converted to radiation interaction parameters. The accuracy of the radiative transfer simulations largely depends on the 'exactness' to which interaction parameters are calculated. Hence, the single scattering properties such as extinction coefficient, single scattering albedo and phase matrix are calculated for various atmospheric constituents, such as participating gases (oxygen and water vapour) in addition to rain parameters. The interaction parameters also depend on the governing characteristics such as size, density and the drop size distribution (DSD). In the present study, the modified gamma distribution (Deirmendjian 1969) that is widely used in literature, has been used as DSD for cloud liquid water and cloud ice parameters. The modified gamma distribution for the number distribution $n(r)$ with four parameters is given by:

$$
n(r)=a r^{\alpha} \exp \left(-b r^{\gamma}\right) .
$$

The modified gamma expression is related to mass density (for liquid or solid) by the following expression:

$$
\begin{aligned}
m & =\int_{0}^{\infty}\left(\frac{4}{3} \pi r^{3}\right) \rho n(r) \mathrm{dr} \\
& =a \rho\left(\frac{4 \pi}{3 \gamma}\right)\left(\frac{\alpha}{\gamma}\right)^{-\frac{(\alpha+4)}{\gamma}} r_{\mathrm{c}}^{\alpha+4} \Gamma\left(\frac{\alpha+4}{\gamma}\right),
\end{aligned}
$$

where $\Gamma$ and $\rho$ represent the gamma distribution function and density of the hydrometeor, respectively. The critical radius $r_{\mathrm{c}}$ appearing in equation (2) is given by:

$$
r_{\mathrm{c}}=(\alpha / \gamma \beta)^{1 / \gamma}
$$




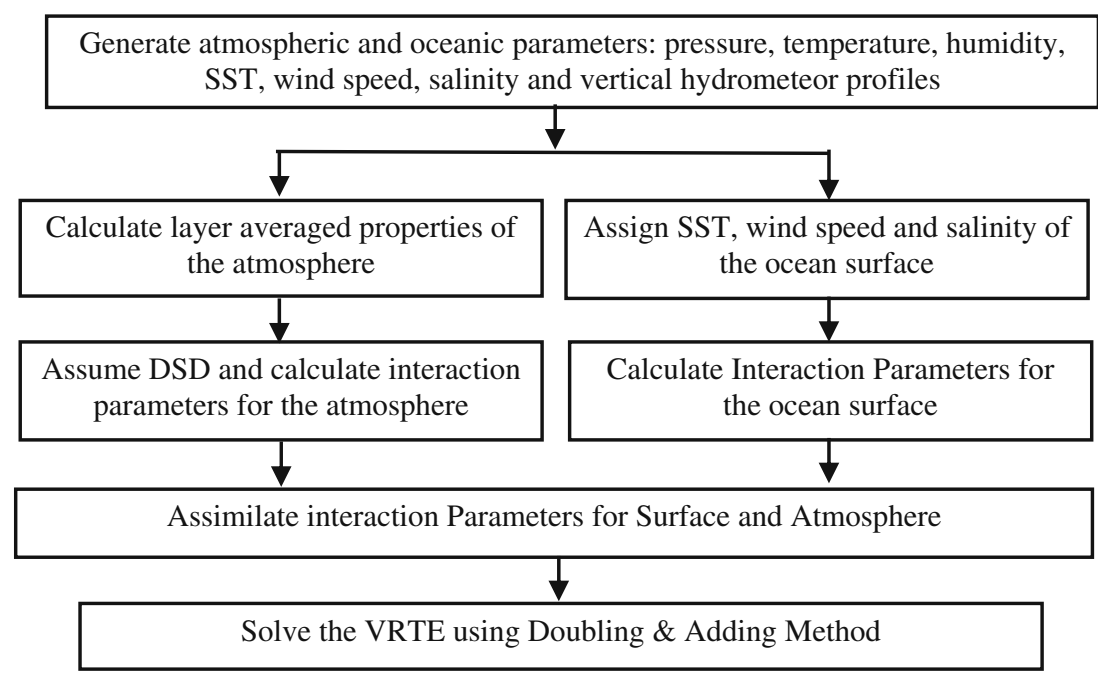

Figure 3. Overview of the forward model developed in modular form.
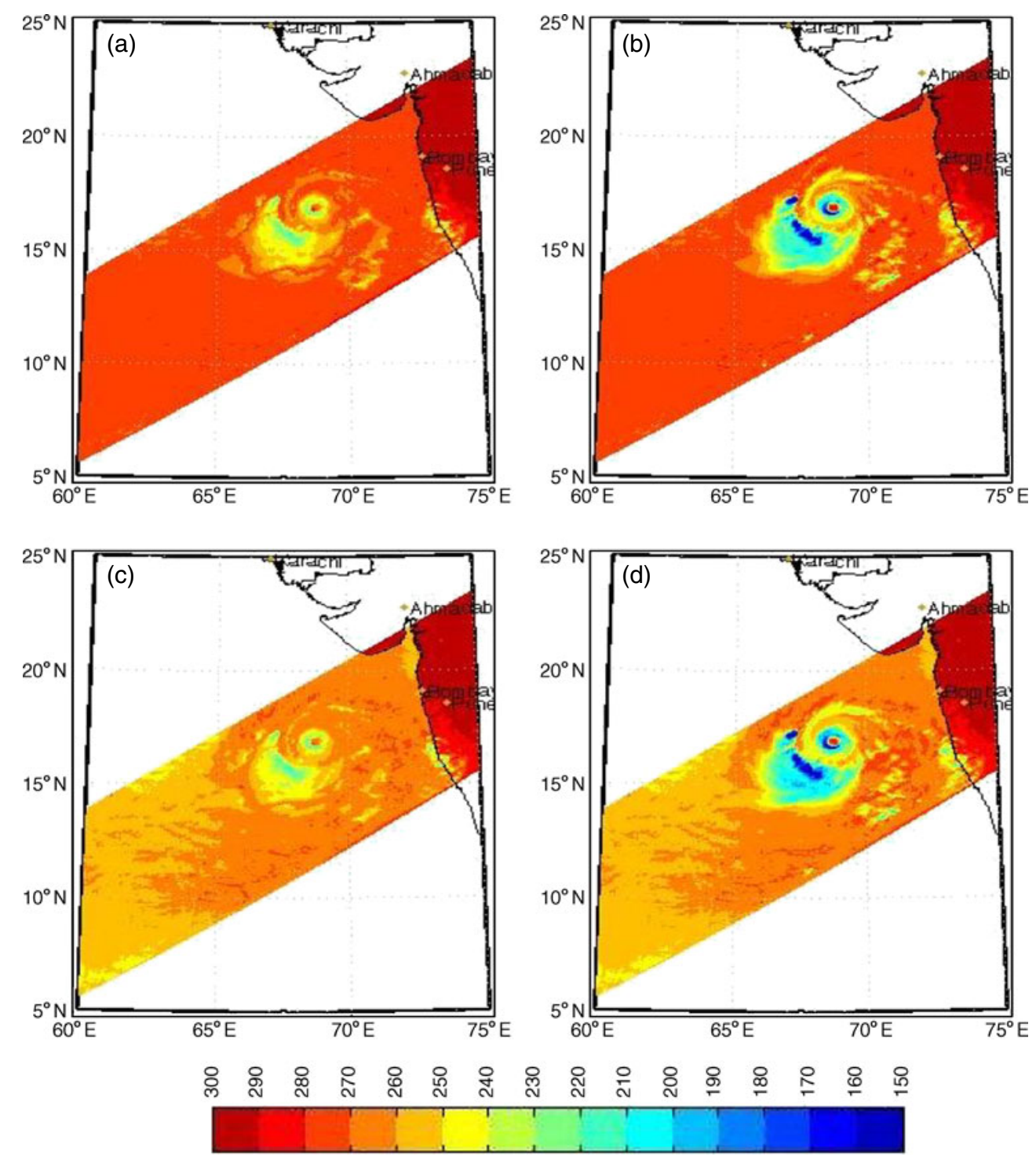

Figure 4. Comparison of radiative transfer simulations with TMI measured brightness temperatures (in K) for (a and $\mathbf{b}$ ) $85 \mathrm{GHz}(\mathrm{V}),(\mathbf{c}$ and $\mathbf{d}) 85 \mathrm{GHz}(\mathrm{H})$ for tropical storm 01A. 


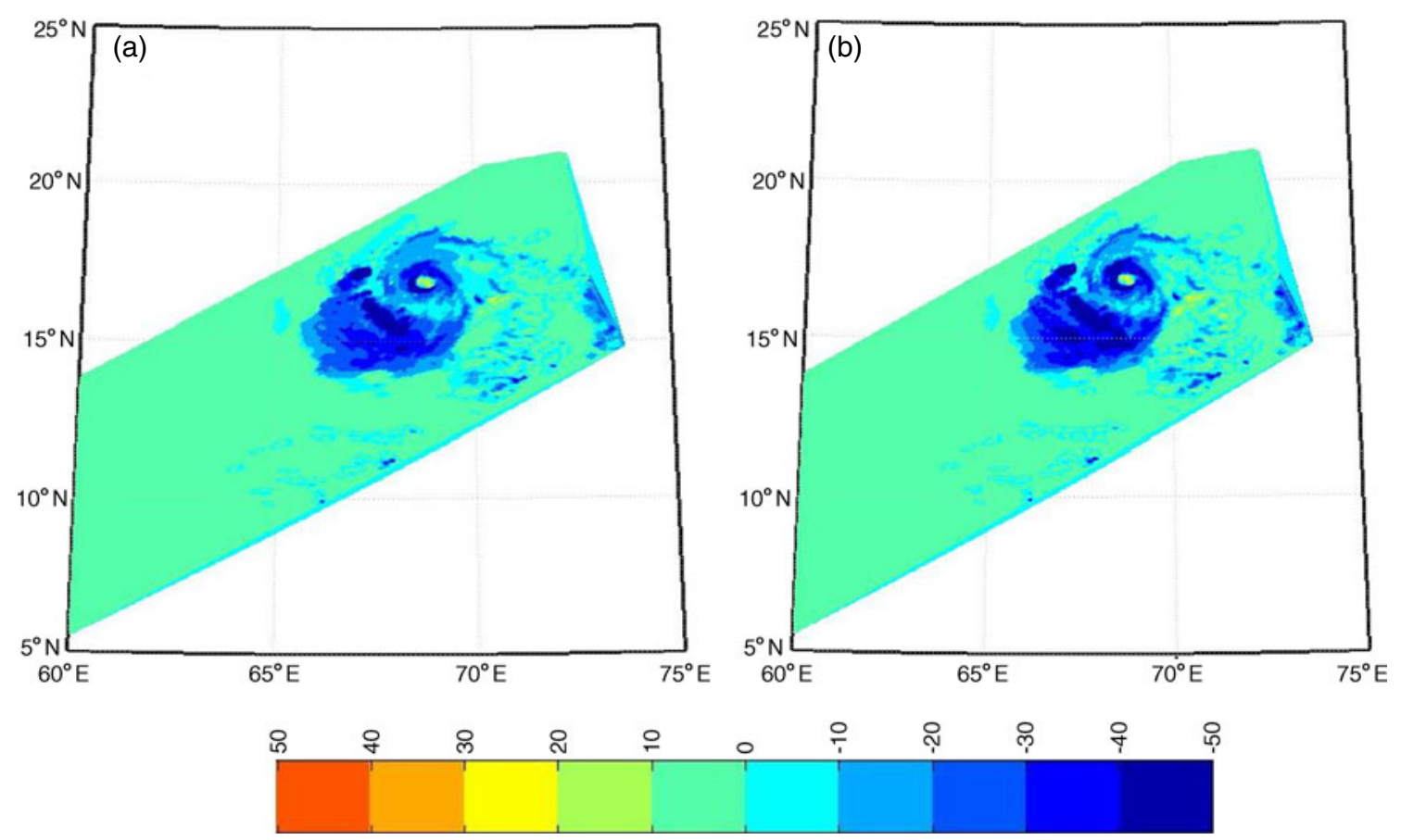

Figure 5. Difference between VRTE simulated and TMI measured brightness temperatures for (a) $85 \mathrm{GHz}(\mathrm{V})$ and (b) $85 \mathrm{GHz}(\mathrm{H})$ channels for tropical storm 01A.

For precipitating quantities, Marshall-Palmer distribution (Marshall and Palmer 1948) is used, which is a special case of the modified gamma function and is given as follows:

$$
n(r)=16 \times 10^{6} \exp \left(-8200 r R_{\mathrm{r}}^{-0.21}\right) \text { in }^{-4} .
$$

In equation (4), $R_{\mathrm{r}}$ refers to surface rain rate in $\mathrm{mm} / \mathrm{h}$. The constants appearing in the modified gamma function are adjusted to match experimental observations for a given temperature and frequencies. For a fuller discussion on the calculation of the interaction parameters, see Ulaby et al (1981).

Simulations for the TOA radiances/brightness temperatures at various microwave frequencies are carried out by solving the vector radiative transfer equation using the adding and doubling method (Deiveegan et al 2008). In the ensuing section, the vector radiative transfer equation and its solution procedure are explained in detail.

\section{The vector radiative transfer equation (VRTE)}

Following Evans and Stephens (1991), the equation of radiative transfer in vector form, for a monochromatic, plane parallel, raining atmosphere that emits/absorbs and/or scatters is given by:

$$
\mu \frac{\mathrm{d} \mathbf{I}}{\mathrm{d} \tau}(\tau, \mu, \phi)=-\mathbf{I}(\tau, \mu, \phi)
$$

$$
\begin{aligned}
& +\frac{\tilde{\omega}}{4 \pi} \int_{0}^{2 \pi} \int_{-1}^{1} P(\mu, \phi ; \tilde{\mu}, \tilde{\phi}) \mathrm{d} \tilde{\mu} \mathrm{d} \tilde{\phi} \\
& +(1-\tilde{\omega}) B(T)\left[\begin{array}{l}
1 \\
0 \\
0 \\
0
\end{array}\right],
\end{aligned}
$$

where $\mu, \phi$ denote the angles representing the spherical coordinate system, $\tilde{\omega}$ refers to the single scattering albedo, $\tau$ denotes the optical depth of the atmosphere, $\mathbf{I}$ refers to the diffuse polarized radiance field expressed in vector components $(I$, $Q, U, V), P$ denotes the scattering phase function or the Muller matrix, and $B$ denotes Planck's spectral blackbody distribution function. The coordinate system is defined such that $\tau$ increases downwards and $\mu$ is positive in the lower hemisphere. The radiation is axisymmetric in the azimuth direction, and is represented in terms of a Fourier series. The discretization in the zenith angle is done using Gaussian quadrature points. The radiance field is represented by the Stokes parameters, quadrature zenith angles and Fourier azimuth modes. The left-hand side term in equation (1) refers to the change in intensity with respect to the optical depth. The first term in the right-hand side of equation (1) refers to radiation attenuation due to absorption and out-scattering, the second term refers to augmentation of radiation due to inscattering along the direction of interest and the 

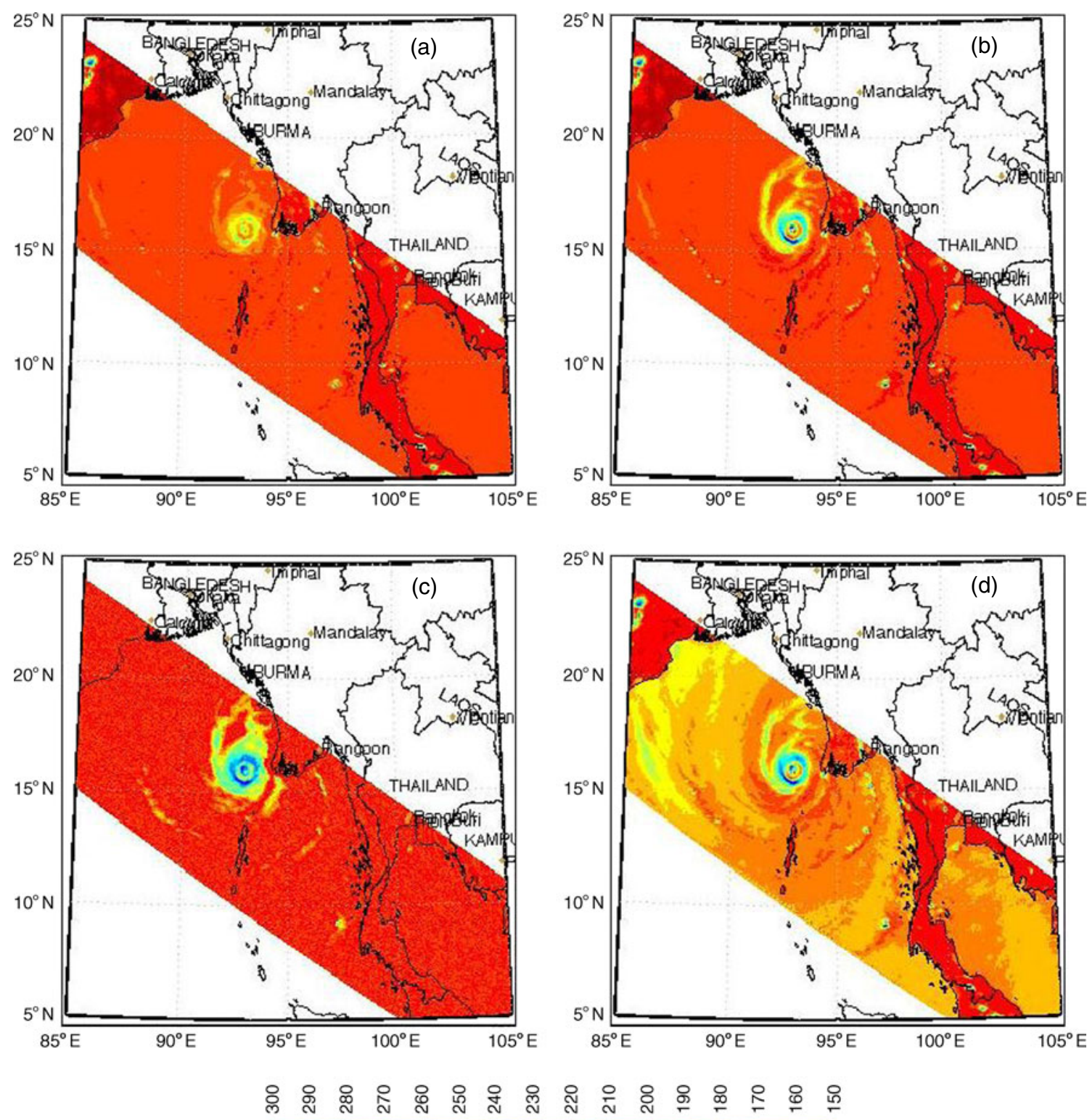

Figure 6. Comparison of radiative transfer simulations with TMI measured brightness temperatures (in K) for (a and $\mathbf{b}$ ) $85 \mathrm{GHz}(\mathrm{V})$, (c and d) $85 \mathrm{GHz}(\mathrm{H})$ for tropical storm Mala.

last term refers to augmentation of radiation due to emission from the hydrometeors and gases in the atmosphere.

In the present study, vertical profiles of hydrometeors are considered at 14 layers of the atmosphere divided unequally between the surface of the earth and the first $18 \mathrm{~km}$ of height. The height of the fourteen layers are $0.5,1,1.5,2,2.5$, $3,3.5,4,5,6,8,10,14$ and $18 \mathrm{~km}$, respectively. The energy balance at each layer requires that the layer-averaged thermodynamic properties such as pressure, temperature and humidity are known $a$ priori. In the present study, the pressure, temperature and humidity at the 14 vertical layers which correspond to raining profiles from the Goddard
Cloud Ensemble (GCE) (Tao and Simpson 1993) model are considered with adequate care to ensure that the profiles are consistent with the thermodynamics of the raining atmosphere from the tropical region. The layer-averaged thermodynamic properties of the raining atmosphere, together with the vertical hydrometeor profiles constitute the input to the VRTE code. The boundary condition for the ocean surface, which is treated as a specular surface is specified in terms of the sea surface temperature (SST), wind speed and salinity. The specular emissivity of the ocean surface shows significant deviations for various wind speeds. The effect of sea surface roughness due to wind speeds has been modeled following Wisler and Hollinger (1977). 

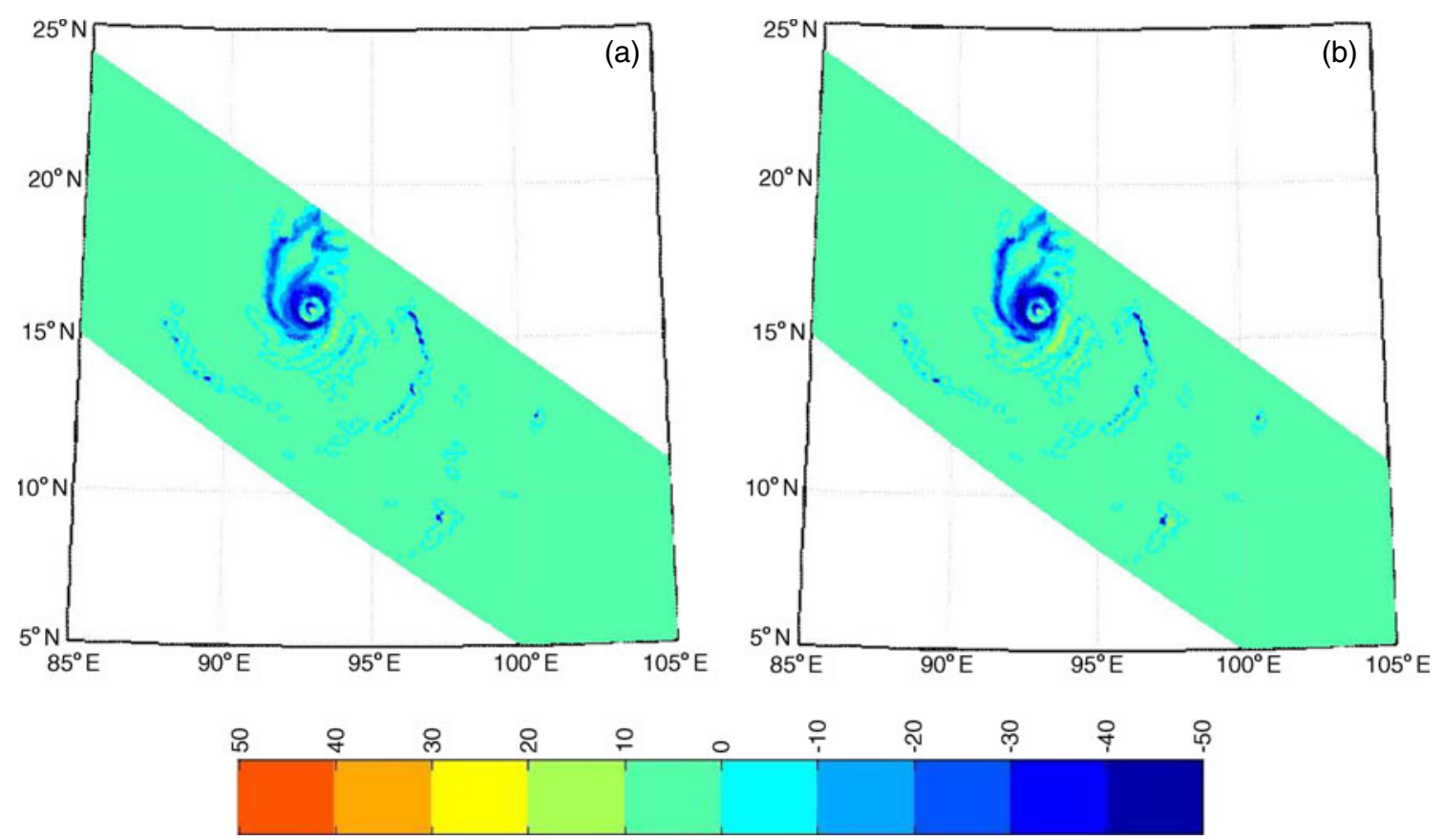

Figure 7. Difference between VRTE simulated and TMI measured brightness temperatures for (a) $85 \mathrm{GHz}(\mathrm{V})$ and (b) $85 \mathrm{GHz}(\mathrm{H})$ channels for tropical storm Mala.

High winds also cause wave breaking in the sea surface, forming foam. Hence, in the present study, the total specular reflectivity from ocean surface is calculated by summing up foam reflectivity weighted with foam coverage and water reflectivity weighted with water coverage. The foam coverage has been modeled following Monahan and O'Muircheartaigh (1986).

The calculation of interaction parameters requires the generation of atmospheric and ocean surface parameters, which is very highly involved wherein the theory of scattering is used in conjunction with an assumption of distribution of the droplet sizes for the hydrometeors, and assumption on the temperature, pressure and humidity in the atmosphere. For further discussion on the vector radiative transfer equation model, see Deiveegan (2007).

\subsection{Solution of vector radiative transfer equations (VRTE)}

An in-house FORTRAN code named MicroTropiques was developed to solve the vector radiative transfer equation based on the adding and doubling method.

The radiative interaction parameters such as extinction coefficient, single scattering albedo, the phase matrix for the atmosphere, the emissivity matrix and the bidirectional reflection matrix for the ocean are calculated from the above-mentioned formulation. In the adding and doubling method, these interaction parameters are calculated for a sub-layer and doubled till the desired layer thickness is reached, and then added to the next layer of different thicknesses.

The solution of the VRTE model gives the simulated brightness temperatures (or radiances) for each viewing angle and frequency, for a downward looking space borne radiometer. In the present study, the brightness temperatures are simulated for the microwave imagers onboard MeghaTropiques as well as the TRMM satellite.

Megha-Tropiques is a joint mission between ISRO, India and CNES, France to understand the role of tropics in global weather and life. The main objective is to study the convective systems and its influence on tropical weather and climate. The Megha-Tropiques satellite payloads are MADRAS, a millimeter wave humidity profiler, SAPHIR and a visible-infrared radiometer for radiation budget (ScaRAB). The satellite is scheduled to be launched during the first half of 2011 onboard the Polar Satellite Launch Vehicle (PSLV) from India. The MADRAS instrument is a 9-channel microwave imager similar to TMI and is the main instrument of Megha-Tropiques. MADRAS is a conical scanning radiometer with a satellite viewing angle of $56^{\circ}$ and horizontal resolution of $6 \mathrm{~km}$ for $157 \mathrm{GHz}$ channel. The operating frequencies of MADRAS is in the range of 18.7 to $157 \mathrm{GHz}$. In the present study, radiative transfer simulations are carried out for all the channels of the MADRAS, with special focus on the 157 GHZ scattering channel that gives information on ice in the upper layers of the atmosphere. 

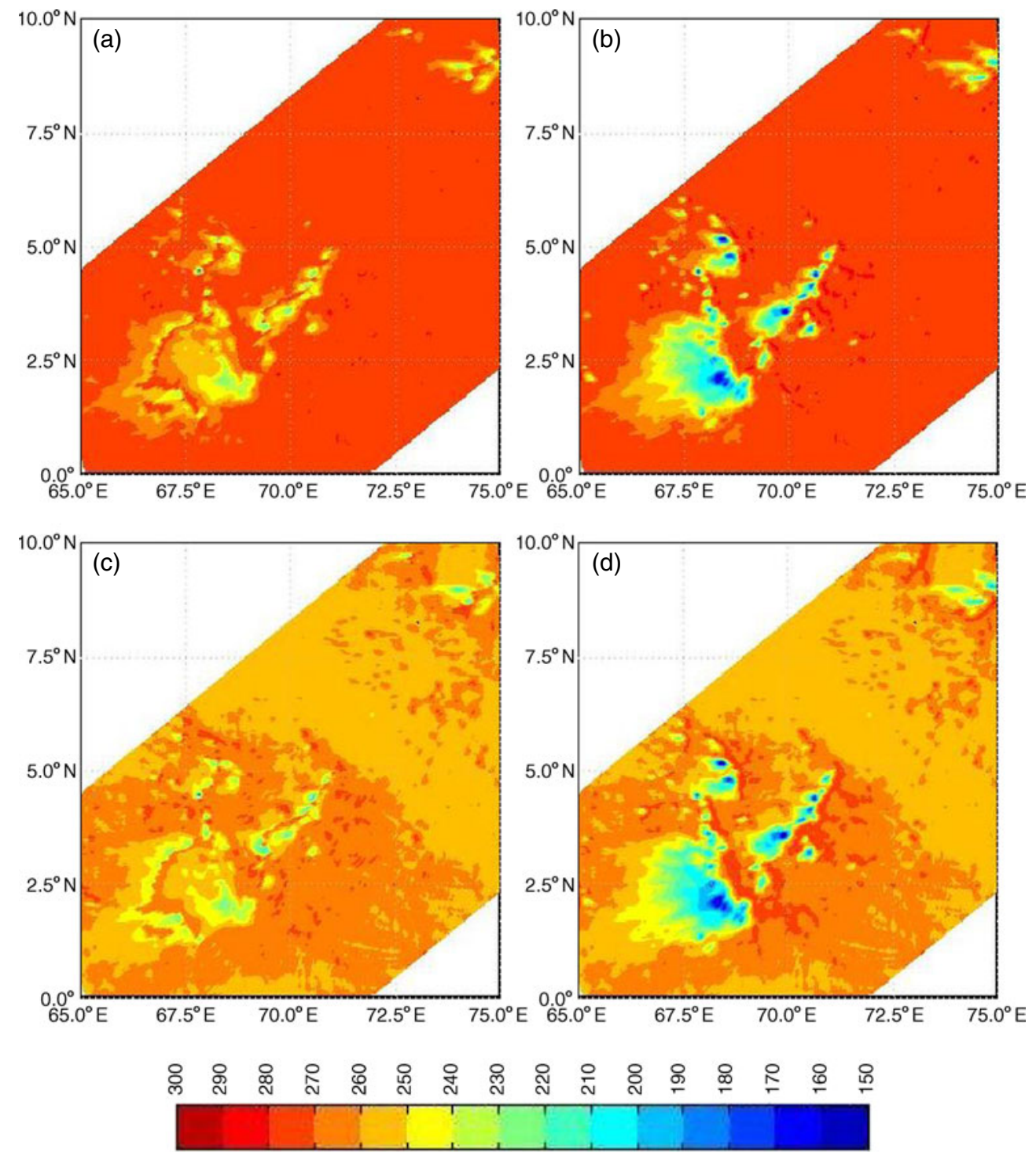

Figure 8. Comparison of radiative transfer simulations with TMI measured brightness temperatures (in K) for (a and $\mathbf{b}$ ) $85 \mathrm{GHz}(\mathrm{V}),(\mathbf{c}$ and $\mathbf{d}) 85 \mathrm{GHz}(\mathrm{H})$ for Southwest monsoon rainfall event.

The satellite viewing angle for the microwave imager onboard TRMM is $52.8^{\circ}$. The radiative interaction parameters for the medium (extinction, scattering albedo and phase matrix) and the surface (bidirectional reflection matrix, emission matrix) are given as inputs for the radiative transfer calculations. An overview of the radiative transfer model is shown in figure 3 .

\subsection{Sample results for VRTE}

Comprehensive validations of the in-house VRTE code for wide scenarios have already been reported in Deiveegan (2007); Deiveegan et al (2008) and Balaji et al (2009). However, it needs to be mentioned that the code originally developed has been modified to accommodate the $157 \mathrm{GHz}$ channel while retaining all the TRMM channels as simu- lations have been done for two imagers. Sample results for radiative transfer simulations of two tropical cyclones and a southwest monsoon rainfall alone have been presented here. A tropical cyclone is typically associated with several types of cloud structures and serves as an excellent test bed to study the effect of rainfall on the brightness temperatures.

\subsubsection{Case 1: Tropical cyclone $01 \mathrm{~A}$}

Radiative transfer simulations for the cyclonic storm 01A, whose eye was centered around $16.9 \mathrm{~N}$ and $68.7 \mathrm{E}$ on May 24, 2001 have been carried out for demonstration. The TRMM satellite made an overpass over the cyclonic region on May 24, 2001. In order to work with realistic hydrometeor profiles, the raining pixels from the $2 \mathrm{~A} 12$ dataset 

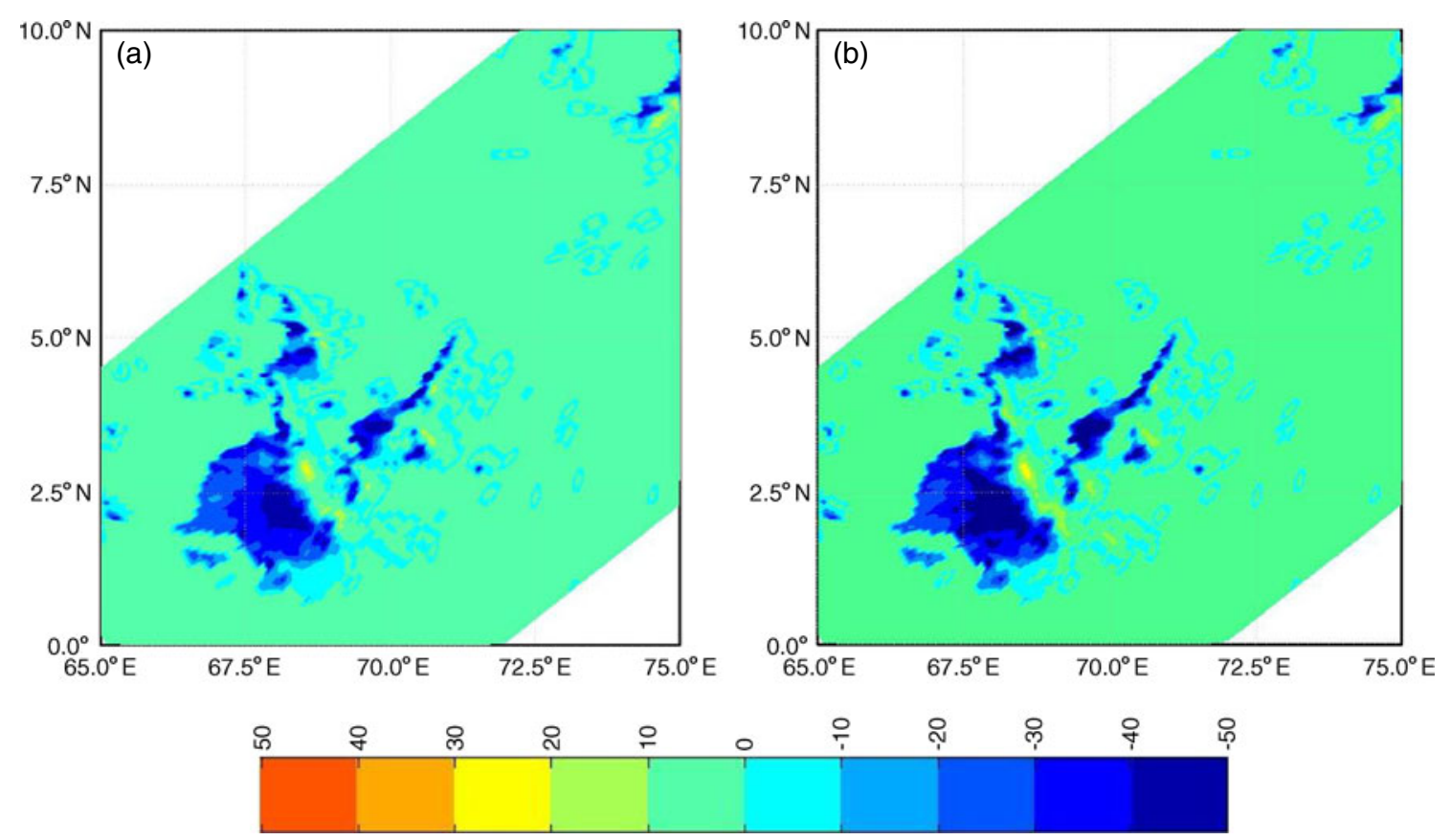

Figure 9. Difference between VRTE simulated and TMI measured brightness temperatures for (a) $85 \mathrm{GHz}(\mathrm{V})$ and (b) $85 \mathrm{GHz}(\mathrm{H})$ channels for Southwest monsoon rainfall event.

[TRMM Data Products (2009)] containing the retrieved hydrometeor profiles from the microwave imager aboard the TRMM satellite (known as TRMM microwave imager - TMI) are used as inputs. A sea surface temperature of $300 \mathrm{~K}$, wind speed of $15 \mathrm{~m} / \mathrm{s}$ and salinity of $35 \mathrm{ppm}$ have been assumed for all the pixels. Sensitivity analysis studies showed that the simulated brightness temperatures in the microwave region for a raining atmosphere are not critically dependent on these parameters. Brightness temperatures are simulated for $10.65 \mathrm{GHz}(\mathrm{V}, \mathrm{H}), 19.35 \mathrm{GHz}(\mathrm{V}, \mathrm{H}), 21.3 \mathrm{GHz}$, $(\mathrm{V}), 37 \mathrm{GHz}(\mathrm{V}, \mathrm{H})$ and $85 \mathrm{GHz}(\mathrm{V}, \mathrm{H})$ channels. However, results for only the $85 \mathrm{GHz}$ channel are presented here. This particular channel has been chosen for presenting the results since higher frequency channels are more sensitive to scattering from rain and ice particles and so throw light on issues like radiometer sensitivity and saturation at high rain rates. Figure 4 shows a comparison of the brightness temperature simulated using VRTE and the TMI measured brightness temperature for $85 \mathrm{GHz}$ channel for the tropical storm under consideration. Figure 5 shows the quantitative comparison of radiative transfer simulations with TMI observations for the cyclone under consideration.

From figures 4 and 5 , it can be observed that the Micro-Tropiques code is able to capture the general features of the cyclone quite well including the eye. Furthermore, the VRTE-simulated brightness temperatures agree fairly well with the TMI measurements with a root mean square error (RMSE) of $21 \mathrm{~K}$ and a correlation coefficient of 0.918 for the vertical polarization channel, and an RMSE of $23 \mathrm{~K}$ and a correlation coefficient of 0.91 for the horizontal polarization channel. On a baseline value (SST of $300 \mathrm{~K}$ ), this error works out to be less than $5 \%$. Figure 5 also shows that the brightness temperature difference between the RT simulations and TMI observations is less than $10 \mathrm{~K}$ at the high rain rate regions, and the difference increases at lower rain rates. This is because at lower rain rates, the humidity and temperature profiles exert a significant influence on the brightness temperatures.

The RMSE mentioned above arises due to two main reasons: (i) errors introduced by the RT simulations and (ii) errors associated with the assumed hydrometeor profiles which are themselves outputs of a retrieval algorithm. However, it is difficult to separate the two errors due to non-availability of measured hydrometeor profiles and simultaneous measurement of brightness temperatures from a space borne radiometer. If one considers the high raining pixels, the error is less than $10 \mathrm{~K}$. From the sensitivity of the $85 \mathrm{GHz}(V)$ temperatures to the ground rain rate it is seen that an RMSE of $20 \mathrm{~K}$ in the brightness temperature translates to an error of about $4 \mathrm{~mm} / \mathrm{h}$ in the ground rain rate. In view of the above, it is clear that for cases of high rainfall the maximum error will be around $2 \mathrm{~mm} / \mathrm{h}$ or less. The maximum rainfall itself among all the scenes considered is about $35-40 \mathrm{~mm} / \mathrm{h}$. Hence, the error 

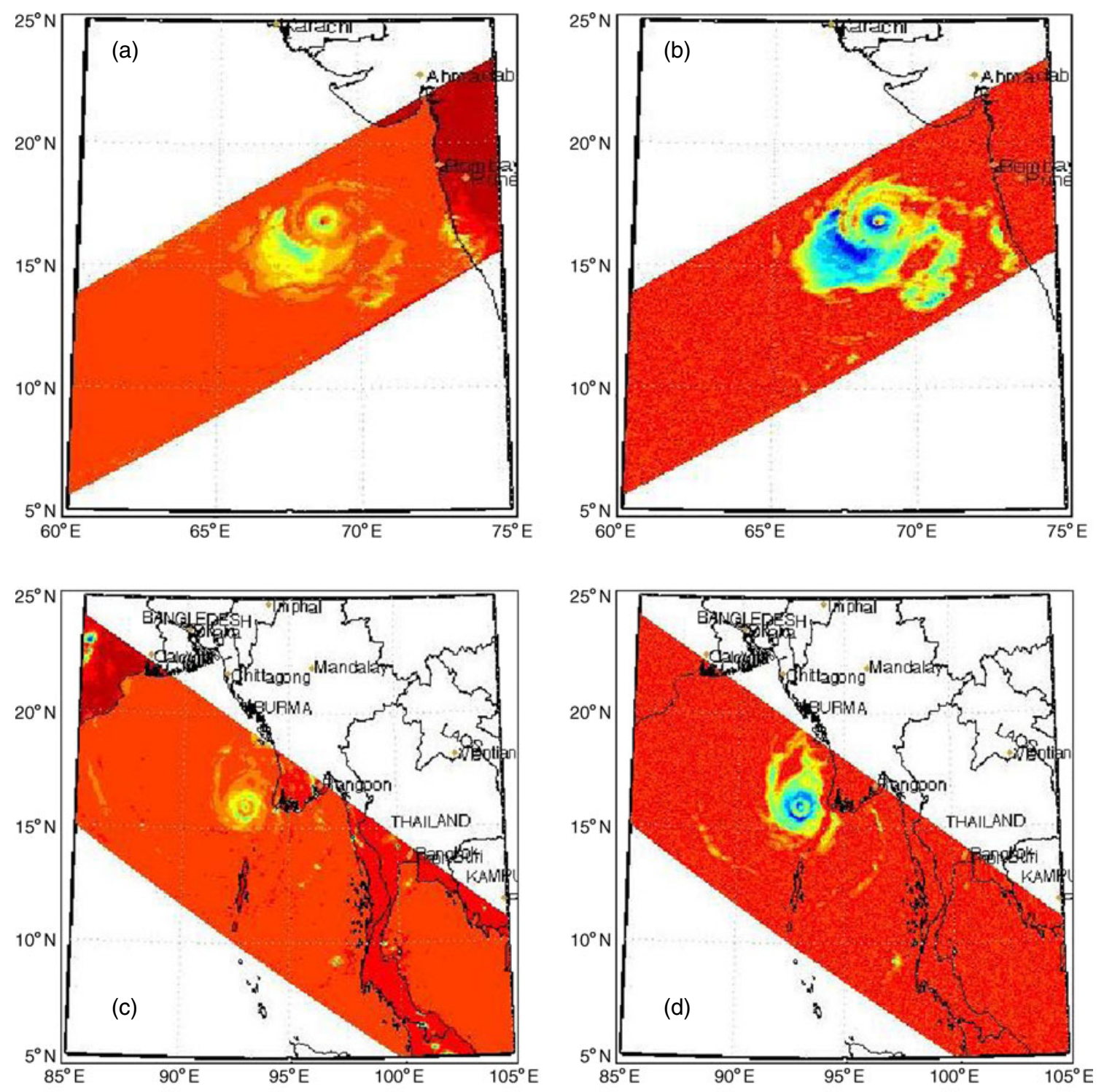

\section{윰 总}

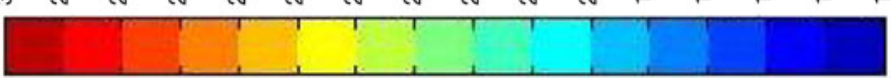

Figure 10. Simulation of brightness temperatures (in K) for tropical storm 01A for (a) $85 \mathrm{GHz}$, (b) $157 \mathrm{GHz}$ and for tropical storm Mala for (c) $85 \mathrm{GHz}$, (d) $157 \mathrm{GHz}$ vertical polarizations.

introduced by RT simulations is not expected to significantly affect ground rain rate estimates if a retrieval algorithm based on these RT simulations is eventually proposed.

\subsubsection{Case 2: Tropical cyclone Mala}

Radiative transfer simulations for the cyclonic storm Mala whose eye was centered around $16 \mathrm{~N}$ and 92.5 E on April 25, 2006 have also been carried out for establishing the capability of the MicroTropiques code. TRMM made an overpass over the Mala cyclonic storm on April 24, 2006. The hydrometeor profiles from the 2A12 dataset are used as inputs. Other inputs are the same as that for the previous case. The brightness temperatures are simulated for the $85 \mathrm{GHz}$ channel. Figure 6 shows a comparison of the brightness temperatures simulated using VRTE with the TMI measured brightness temperature, for the $85 \mathrm{GHz}$ channel for the tropical storm under consideration. The quantitative comparison between radiative transfer simulations and TMI observations is shown in figure 7 . 


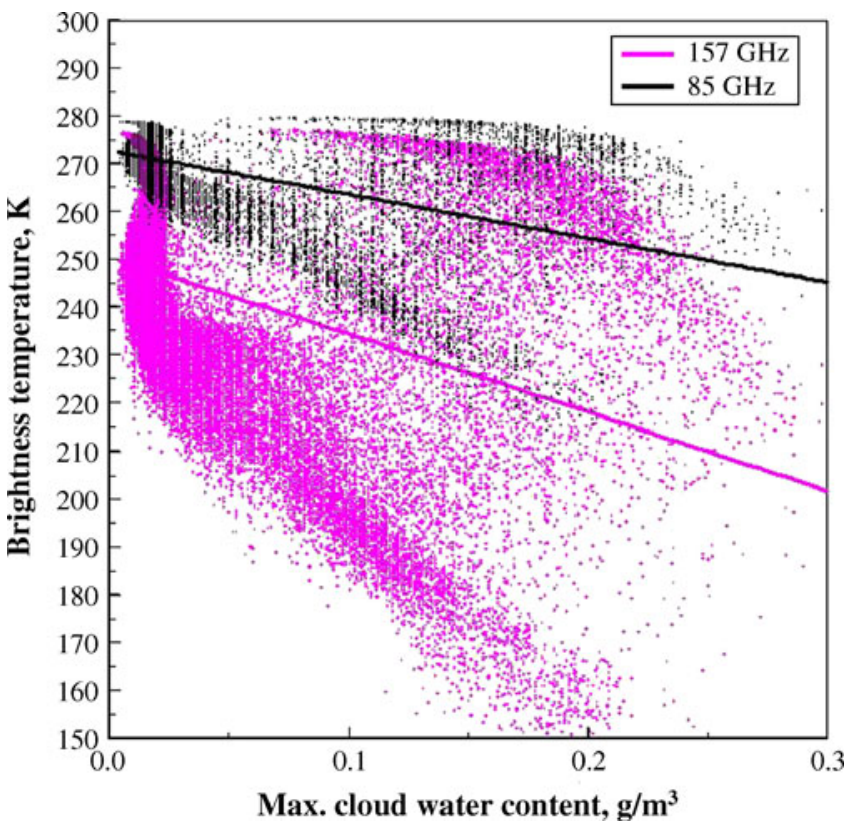

Figure 11. Effect of cloud liquid water on brightness temperatures for high frequency channels.

From figures 6 and 7, it can be seen again that the Micro-Tropiques simulations agree fairly well with the TMI measurements. An RMSE of $16 \mathrm{~K}$ and a correlation coefficient of 0.873 for the vertical polarization channel, and an RMSE of $17.5 \mathrm{~K}$ and a correlation coefficient of 0.852 for horizontal polarization channel confirm the adequacy of radiative transfer simulations.

\subsubsection{Case 3: Southwest monsoon rainfall}

The capability of the Micro-Tropiques code to simulate brightness temperatures for various types of rain events is demonstrated by performing the radiative transfer simulations for a southwest monsoon rain scene during the year 2005. This particular monsoon brought heavy rain throughout the Indian region. In particular, Mumbai city recorded an all time record rainfall of over $100 \mathrm{~cm} /$ day on July 26, 2005.

TRMM made an overpass over the monsoon region bounded by $65-75 \mathrm{E}$ and $0-10 \mathrm{~N}$ on July 28,2005 . As in the previous cases, the hydrometeor profiles from the $2 \mathrm{~A} 12$ dataset are used as inputs. Other inputs are the same as that for the previous case. The brightness temperatures are simulated for the $85 \mathrm{GHz}$ channel. Figure 8 shows a comparison of the brightness temperature simulated using VRTE and TMI measured brightness temperature for $85 \mathrm{GHz}$ channel for the southwest monsoon rain event. A contour plot of the difference between the VRTE simulations and TMI measurements is shown in figure 9 .

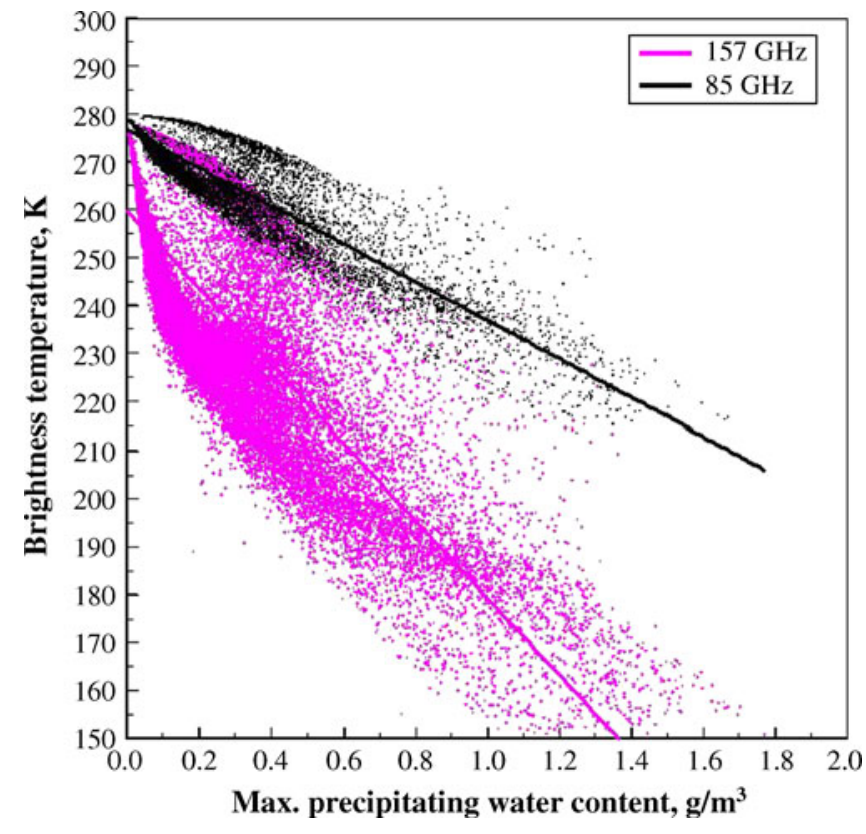

Figure 12. Effect of precipitating water on brightness temperatures for high frequency channels.

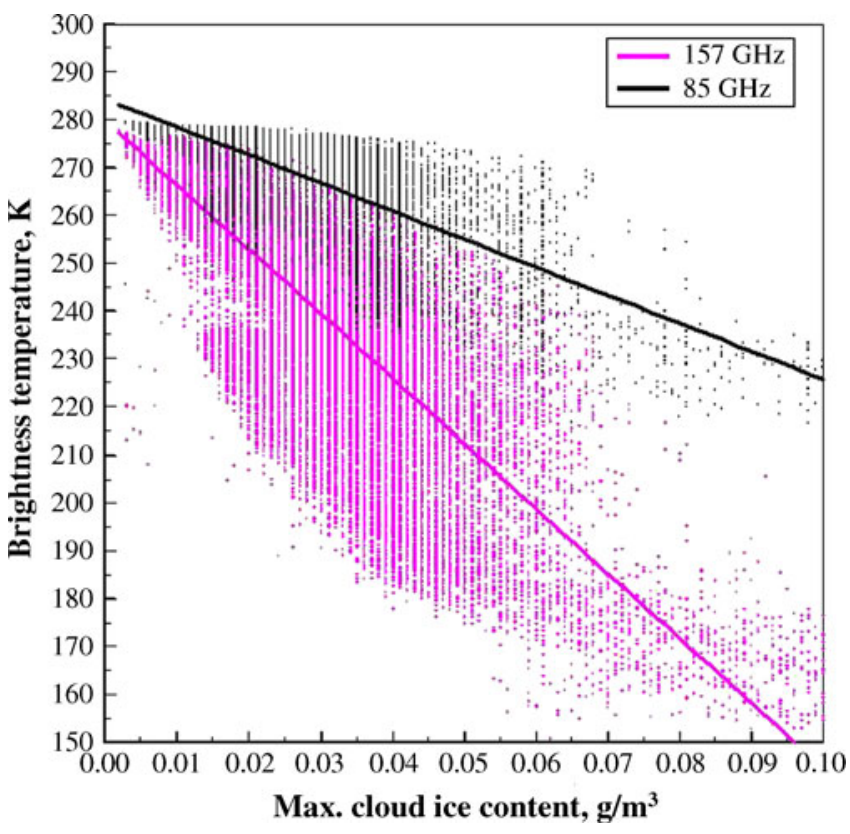

Figure 13. Effect of cloud ice on brightness temperatures for high frequency channels.

From figures 8 and 9 , it can be seen that the Micro-Tropiques code performs satisfactorily in simulating the brightness temperature for southwest monsoon rain event. An RMSE of $20 \mathrm{~K}$ and a correlation coefficient of 0.851 for the vertical polarization channel, and an RMSE of $22.5 \mathrm{~K}$ and correlation coefficient of 0.874 for horizontal polarization channel were obtained for the simulations. 


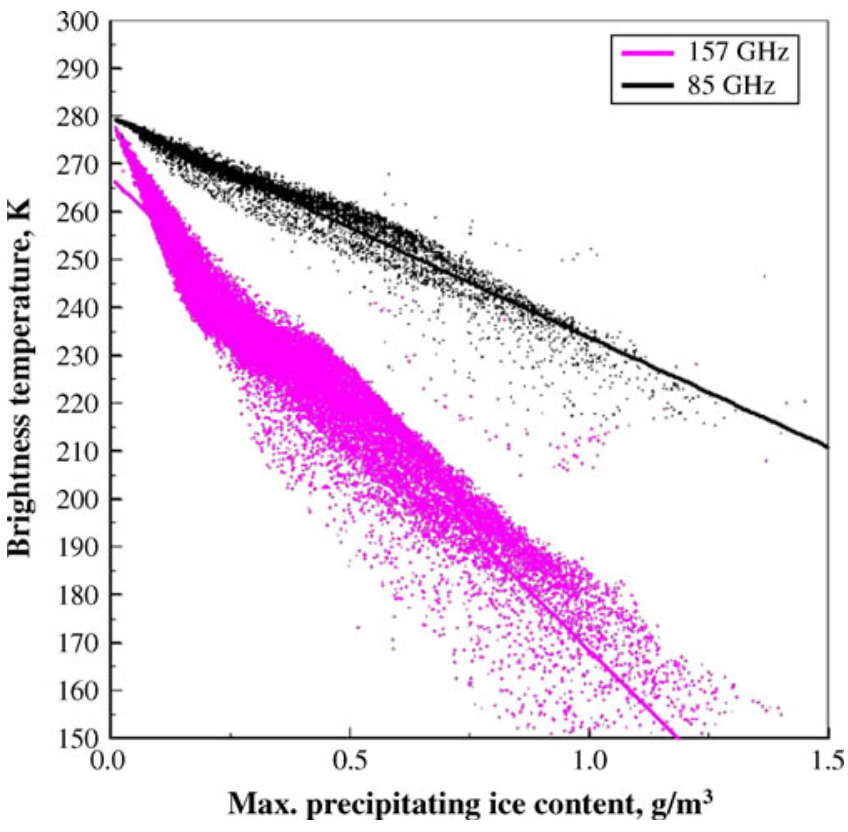

Figure 14. Effect of precipitating ice on brightness temperatures for high frequency channels.

\subsection{Simulations for the $157 \mathrm{GHz}$ brightness temperature}

It has been observed previously in literature that high frequency channels are more sensitive to rain from ice clouds due to scattering. The proposed Indian climate research satellite Megha-Tropiques has this specific $157 \mathrm{GHz}$ channel to delineate ice and rain structures and to provide new information on ice at cloud tops, precipitation estimation over land and water vapour retrieval from lower levels at a $6-\mathrm{km}$ horizontal resolution level. In order to study the performance of the $157 \mathrm{GHz}$ channel, radiative transfer simulations have been carried out for the tropical cyclones $01 \mathrm{~A}$ and Mala for both the vertical and horizontal polarizations. Figure 10 shows a comparison of $157 \mathrm{GHz}$ channel with $85 \mathrm{GHz}$ from VRTE simulations. From figure 10 , it can be seen that the $157 \mathrm{GHz}$ reveals a further dip in the brightness temperatures close to the eye, suggestive of its increased ability to pick up ice/rain signature. In view of this, in the context of rainfall retrievals with multi-channel sensors, this high frequency channel is of great use in delineating ice/rain structures.

\subsection{Effect of hydrometeors on $157 \mathrm{GHz}$ simulations}

From the previous sections, it is seen that the $157 \mathrm{GHz}$ channel shows more sensitivity towards ice/rain signature than the $85 \mathrm{GHz}$ channel. A parametric study has been conducted systematically to observe the sensitivity of the $85 \mathrm{GHz}$ and

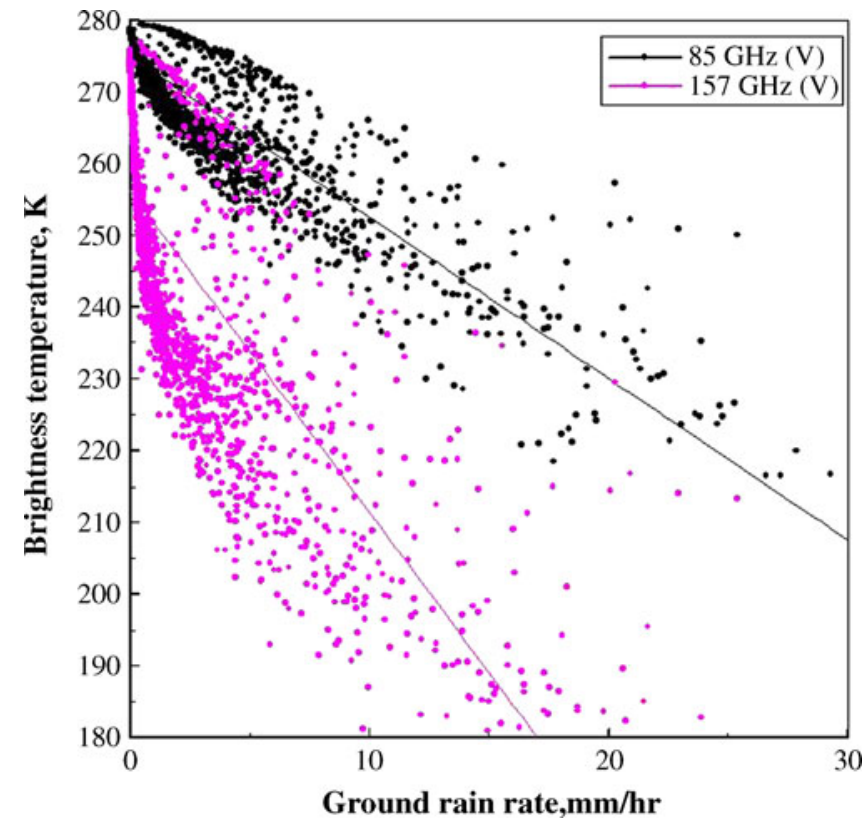

Figure 15. Variation of 85 and $157 \mathrm{GHz}$ brightness temperatures with ground rain rate.

the $157 \mathrm{GHz}$ channels for various hydrometeors. Figures 11-14 show the effect of each of the four hydrometeors namely cloud liquid water, precipitating water, cloud ice and precipitating ice on simulated brightness temperature for $85 \mathrm{GHz}$ and $157 \mathrm{GHz}$ vertical polarization, using the VRTE code.

The figures inarguably demonstrate that the $157 \mathrm{GHz}$ channel is more sensitive to the hydrometeors than the $85 \mathrm{GHz}$ channel, as seen from the increased slope. Figure 14 clearly shows the superiority of the $157 \mathrm{GHz}$ channel in picking up the ice structure. Further, from figures 12 and 14 it can be seen that a good correlation exists between the precipitating hydrometeors and the $157 \mathrm{GHz}$ brightness temperature. This relation can be used to retrieve the instantaneous surface rain rate parameter, which is one of the useful rainfall products to be retrieved from passive microwave observations. Figure 15 shows the variation of the $85 \mathrm{GHz}$ and the $157 \mathrm{GHz}$ brightness temperatures with ground rain rate, derived from the precipitating water content from the first layer using the Marshall-Palmer distribution, given by:

$$
R_{\mathrm{r}}=17.83 P W_{1}^{1.19},
$$

where $R_{\mathrm{r}}$ is the rain rate in $\mathrm{mm} / \mathrm{h}, P W_{1}$ is the precipitating water content in the first layer in $\mathrm{g} / \mathrm{m}^{3}$. Equation (6) is obtained by relating the expression for $n(r)$ from the Marshall-Palmer given by equation (4) to the mass density given by equation (2). From figure 15, it can be observed that the accuracy in the retrieval of surface rain rate 


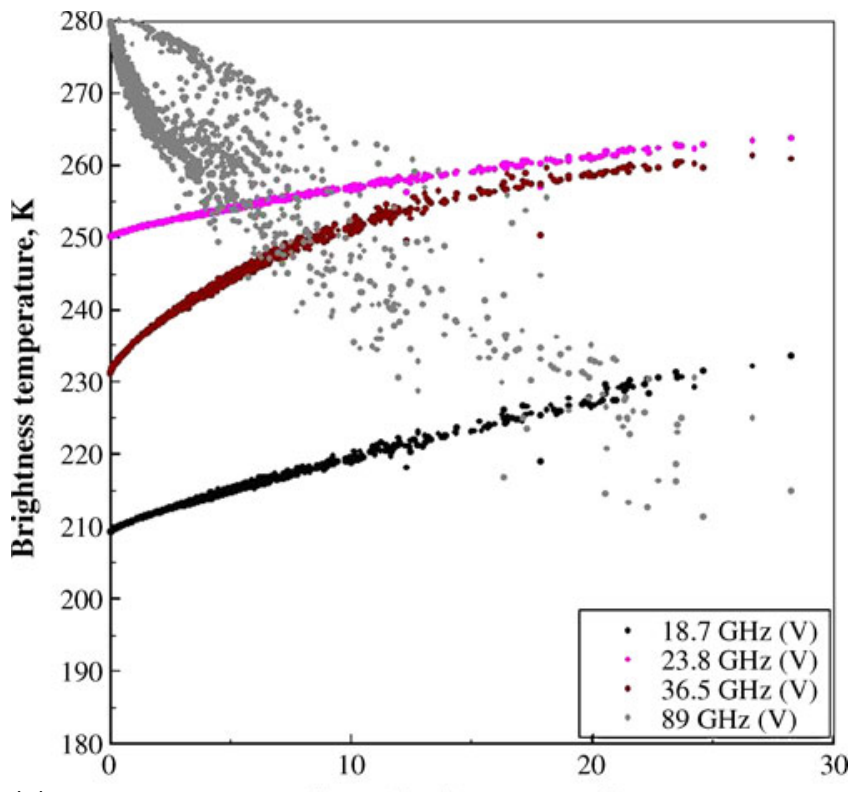

(a)

Ground rain rate, $\mathrm{mm} / \mathrm{hr}$

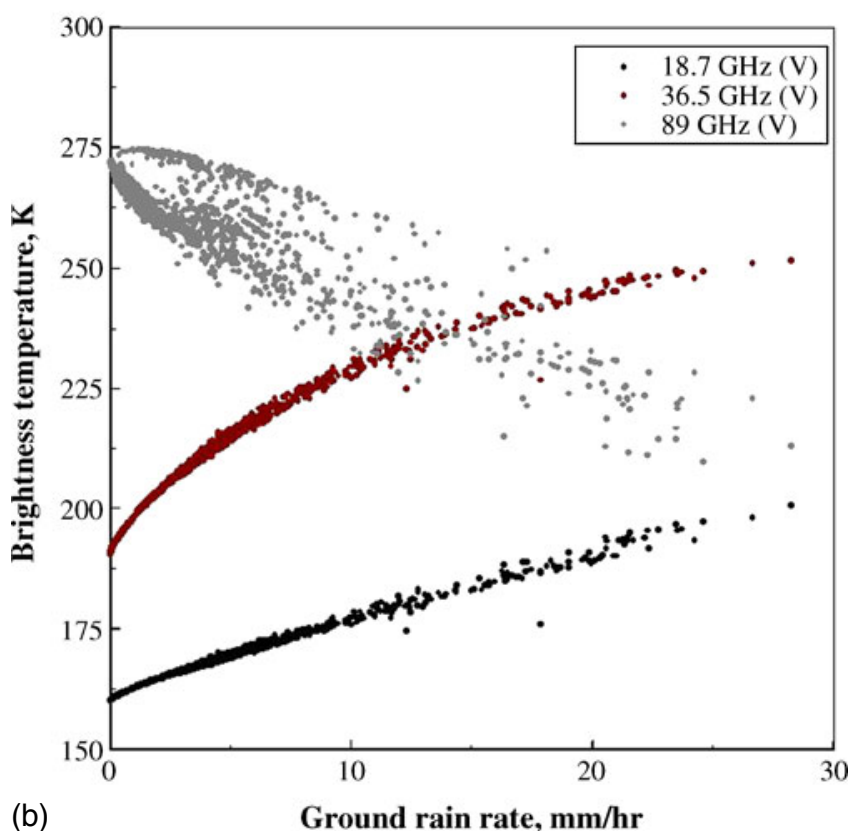

Figure 16. Variation of brightness temperatures with ground rain rate for MADRAS channels: (a) vertical polarization and (b) horizontal polarization.

can be improved by adding the more sensitive $157 \mathrm{GHz}$ channel brightness temperature information instead of the $85 \mathrm{GHz}$ channel.

\subsection{Simulations for other channels}

Radiative transfer simulations are also carried out for other frequencies in the MADRAS imager of Megha-Tropiques. Figure 16(a and b) shows the variation of brightness temperatures with respect to the surface rain rate calculated using equation (6) for two polarizations: vertical and horizontal, respectively. It can be seen that the trend of brightness temperature variation with rain rate as seen from figure 16( $a$ and $b$ ) agrees very well with the stated mission objectives for different channels as shown in table 1.

The emission channels (18.7 and $23.8 \mathrm{GHz}$ ) show increasing brightness temperatures with increasing rain, consistent with the fact that a higher rain rate leads to increased emission leading to increased brightness temperatures. For the $36.5 \mathrm{GHz}$ scattering channel, though, both emission and scattering are equally important; the former tends to increase the brightness temperature, while the latter tries to decrease it. These opposing effects are responsible for (i) $36.5 \mathrm{GHz}$ temperatures being lower than the $23.8 \mathrm{GHz}$ temperatures and (ii) $36.5 \mathrm{GHz}$ brightness temperatures saturating at rain rates beyond $20 \mathrm{~mm} / \mathrm{h}$.

The $89 \mathrm{GHz}$ brightness temperatures show a very interesting trend. First, these brightness temperatures decrease rapidly with increasing rain rate as a result of heavy out-scattering by rain/ice particles. Second, the brightness temperatures corresponding to $89 \mathrm{GHz}$ can be roughly grouped into two with different slopes. These correspond to convective and stratiform pixels in the raining scene.

\section{Need for fast radiative transfer simulations}

Due to the complexity involved in the radiation modeling of raining atmosphere, the in-house VRTE takes about $6 \mathrm{~s}$ for the simulation of brightness temperatures for a given cloud scene or a pixel. For typical meteorological applications, the microwave radiometer in the TRMM satellite makes a measurement of about 116 profiles per second. Hence, in order to develop an algorithm to retrieve the hydrometeor profiles, there is a need to speed up the computational time involved in the radiative transfer simulations for real time processing of satellite images with a view to estimate the vertical rain structures.

\section{Artificial neural networks (ANN) based fast radiative transfer model (AFRT)}

Neural networks have been widely recognized as one of the simplest techniques to train and mimic the complex relationship between input and target values that arises from meteorological data. Churnside et al (1994) used neural networks to obtain the vertical temperature profile of the earth's atmosphere using microwave radiometer 


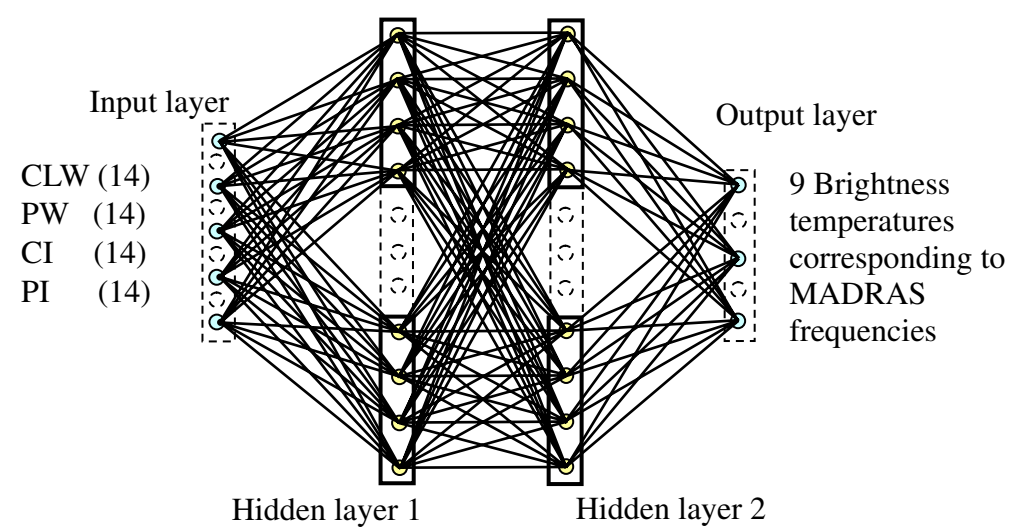

Figure 17. Typical ANN architecture with two hidden layers.
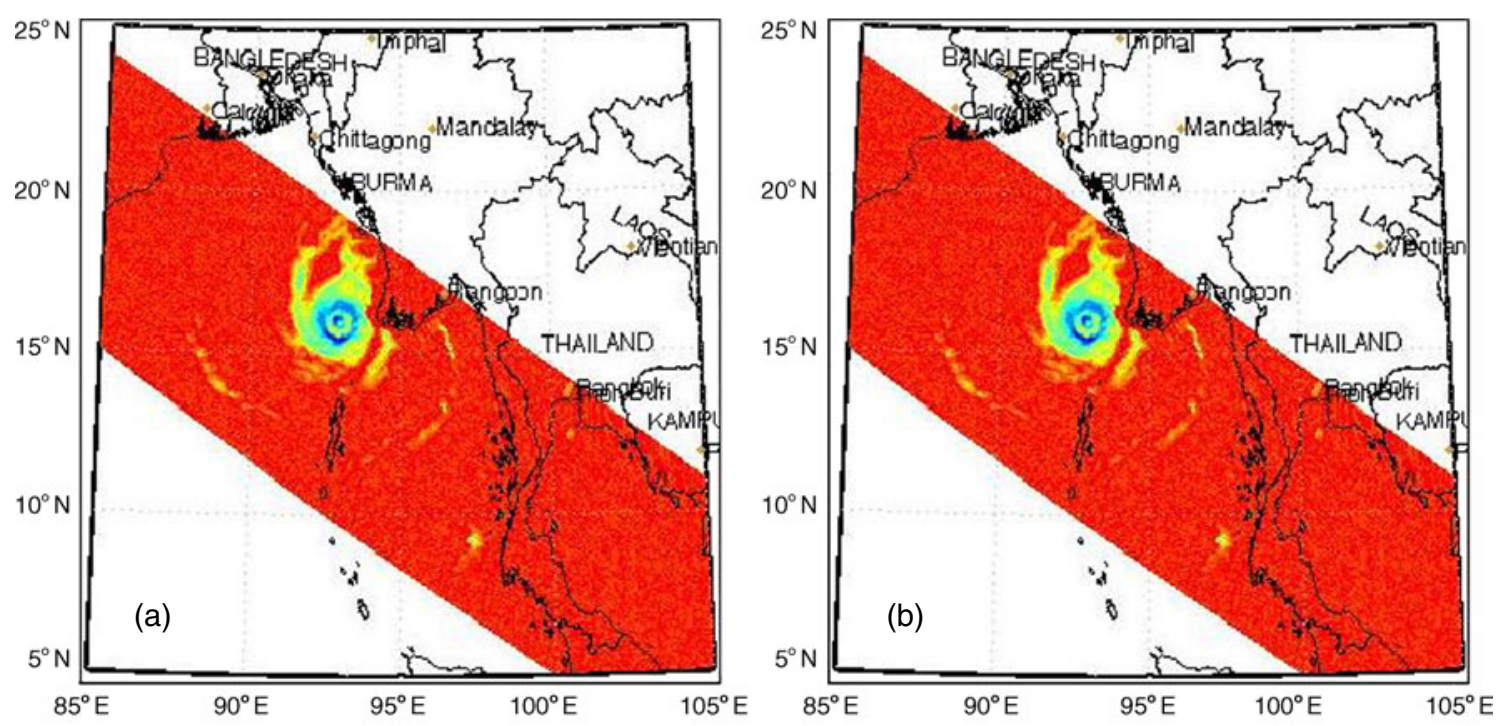

\section{융}

Figure 18. Comparison of brightness temperatures simulated at $157 \mathrm{GHz}$ by (a) VRTE and (b) AFRT.

data. They have shown that in certain cases the neural networks produced better results than a statistical inversion technique and the overall RMS error is only $8 \%$ worse when compared to optimized statistical retrievals.

Lei Shi (2000) used ANN to retrieve temperature values at 26 pressure levels corresponding to those used in the National Center for Environmental Prediction (NCEP) analysis using 15 brightness temperatures corresponding to Advanced Microwave Sounding Unit (AMSU-A) channels. The retrieval of temperature and dew point profiles using the infrared and the microwave brightness temperatures from a polar orbiting satellite using ANN has been demonstrated by Kuligowski and Barros (2001). They found that temperature retrievals using neural networks have a large error while the dew point retrievals showed a consistent improvement.

Zhigang et al (2005) used a back propagation neural network to retrieve atmospheric temperature profiles from 16 AMSU-A measurements over East Asia and collocated radiosonde observations. Their results showed that neural network retrievals can significantly improve results in all weather conditions, compared to a multi-linear regression technique. Chevallier et al (1998) used neural networks for accurately deriving the long-wave radiation budget from the top-of-atmosphere to the surface and compared the network performance with two radiative transfer models, line-by-line model and a band model. They were able to achieve 
better results with a much lower computational time using neural networks.

Schwander et al (2001) undertook a new approach to reduce the computational time involved in the execution of the radiative transfer model using neural networks. They have used neural network to simulate radiances in UV and visible spectral ranges. However, very few authors have reported the use of neural networks for simulation of radiative transfer in microwave radiances, which is essential for candidate retrieval strategies such as genetic algorithm, simulated annealing or Markov chain Monte Carlo method based Bayesian technique. These retrieval techniques in general minimize a residue of the form

$$
R^{2}=\sum_{i=1}^{N}\left(I_{\mathrm{sim}, i}-I_{\mathrm{sat}, i}\right)^{2},
$$

where $I$ is the intensity either simulated (given by subscript 'sim' in equation (7)) or measured (given by 'sat') by the satellite and $i$ refers to the channel number. The goal of the retrieval is to determine the state of the atmosphere characterized by pressure, temperature, humidity and hydrometeors in the vertical direction along with SST and the emissivity of the sea surface that results in an acceptable value of $R$. In other words, the retrieval problem reduces to a minimization problem in $R^{2}$. In view of the ill-posedness of the retrieval problem wherein theoretically more than one $X$ can result in the same $R^{2}$, it is pertinent to identify the correct $X$ by using physical and thermodynamic arguments. This necessitates the use of data-driven approaches, where the solution space is thoroughly and exhaustively searched. Consequently, repeated solutions to the radiative transfer model are inevitable for an accurate and robust retrieval.

In consideration of the above reasons, a retrieval ready-fast radiative transfer model based on ANN is proposed to speed up the simulations of brightness temperatures for MADRAS. This is expected to be useful to the community at large. A typical neural network architecture consists of several layers; the first layer is the input layer, last layer is the output layer, and these are connected by one or more hidden layers, as shown in figure 17 . While the number of neurons in each hidden layer can be chosen arbitrarily, the input layer has a number of neurons that is equal to the number of input parameters and the output layer has a number of neurons that equals the number of output parameters. All the neurons in the input, hidden and output layers are interconnected with an associated weight.
Table 2. Range of precipitation parameters.

\begin{tabular}{lcc}
\hline Hydrometeor & $\begin{array}{c}\text { Min } \\
\left(\mathrm{g} / \mathrm{m}^{3}\right)\end{array}$ & $\begin{array}{c}\text { Max } \\
\left(\mathrm{g} / \mathrm{m}^{3}\right)\end{array}$ \\
\hline Cloud liquid water & 0 & 0.497 \\
Precipitating water & 0 & 1.492 \\
Cloud ice & 0 & 0.154 \\
Precipitating ice & 0 & 1.299 \\
\hline
\end{tabular}

Table 3. Range of brightness temperatures for MADRAS channels.

\begin{tabular}{lccc}
\hline $\begin{array}{c}\text { Frequency } \\
(f)(\mathrm{GHz})\end{array}$ & $\begin{array}{c}\text { Polarization } \\
(p)\end{array}$ & $\begin{array}{c}T_{f, p, \max } \\
(\mathrm{K})\end{array}$ & $\begin{array}{c}T_{f, p, \min } \\
(\mathrm{K})\end{array}$ \\
\hline 18.7 & $\mathrm{~V}$ & 236 & 209 \\
18.7 & $\mathrm{H}$ & 206 & 160 \\
23.8 & $\mathrm{~V}$ & 264 & 250 \\
36.5 & $\mathrm{~V}$ & 253 & 225 \\
36.5 & $\mathrm{H}$ & 262 & 230 \\
89.0 & $\mathrm{~V}$ & 280 & 193 \\
89.0 & $\mathrm{H}$ & 274 & 192 \\
157.0 & $\mathrm{~V}$ & 277 & 145 \\
157.0 & $\mathrm{H}$ & 277 & 145 \\
\hline
\end{tabular}

Table 4. Network performance of various architectures.

\begin{tabular}{lcc}
\hline $\begin{array}{l}\text { ANN } \\
\text { architecture }\end{array}$ & $\begin{array}{c}\text { Maximum } \\
\text { RMSE (K) }\end{array}$ & $R^{2}$ \\
\hline $56-20-9$ & 0.22 & 0.999 \\
$56-30-9$ & 0.18 & 0.999 \\
$56-40-9$ & 0.23 & 0.999 \\
\hline
\end{tabular}

\subsection{Generation of database}

Statistics-based methods, such as ANN, are largely data-driven and hence the generation of database is of paramount importance. A large database is generated by considering the snapshots of rainy pixels from seven tropical storm events over the North Indian Ocean region that occurred between 2000 and 2006. Sea surface temperatures (SST) of $300 \mathrm{~K}$, wind speed of $15 \mathrm{~m} / \mathrm{s}$ and a salinity of $35 \mathrm{PPM}$ have been assumed for the radiative transfer simulations.

The frequencies considered in the present study correspond to the MADRAS instrument on the Megha Tropiques (Srinivasan and Narayanan 2003); 18.7, 23.8, 36.5, 89 and $157 \mathrm{GHz}$. There are four hydrometeors for every height and with 14 vertical layers under consideration, the total number of hydrometeors turns out to be 56 .

\section{Results and discussion}

The a priori database which is obtained by solving the VRTE for various rain scenes is used for developing the AFRT model. As mentioned earlier, 
Table 5. RMSE of brightness temperatures for MADRAS channels

\begin{tabular}{lccccccccc}
\hline $\begin{array}{l}\text { Frequency } \\
\text { (GHz) }\end{array}$ & 18.7 & 18.7 & 23.8 & 36.5 & 36.5 & 89 & 89 & 157 & 157 \\
\hline $\begin{array}{l}\text { Polarization } \\
\text { RMSE (K) }\end{array}$ & $\mathrm{V}$ & $\mathrm{H}$ & $\mathrm{V}$ & $\mathrm{V}$ & $\mathrm{H}$ & $\mathrm{V}$ & $\mathrm{H}$ & $\mathrm{V}$ & $\mathrm{H}$ \\
\hline
\end{tabular}

the $2 \mathrm{~A} 12$ dataset containing the retrieved hydrometeor profiles from the TRMM is used as inputs in order to work with realistic hydrometeor profiles. A total of 41,180 profiles from seven different rain scenarios captured by the TRMM satellite over the North Indian Ocean region during 2000-2006 have been considered for analysis. The datasets are classified into two sets; the first set of data consisting of 29,171 profiles ( $~ 70 \%$ of the total number of profiles) is used for training the network while the remaining profiles are used for testing purposes. The inputs (14 layers $\times 4$ hydrometeors) and the outputs (9 brightness temperatures corresponding to MADRAS frequencies) are normalized against their respective maximum and minimum values before they are input to the network. The range of the hydrometeor parameters used for normalization is given in table 2 . The range of simulated brightness temperatures for the MADRAS channels is given in table 3 . The back propagation neural network algorithm available in commercial package MATLAB is used for training and simulation of the network. The network is trained for 500 epochs. A neuron independence study has been carried out by training three different architectures and the network performances are tabulated in table 4. From the table, it can be seen that the architecture with 30 neurons in the hidden layer has the least RMSE of $0.18 \mathrm{~K}$. This network is chosen for further simulations.

Table 5 shows the root mean square error (RMSE, in K) between the AFRT model simulated brightness temperatures (56-30-9) and VRTE simulations. The very low values of RMSE confirm the adequacy of the neural network to capture the physics associated with the radiative transfer in the raining atmosphere. Figure 18 shows a comparison of brightness temperatures simulated by VRTE with those predicted by the AFRT for the $157 \mathrm{GHz}$ for a tropical storm Mala whose eye was centred around $16 \mathrm{~N}$ and $93 \mathrm{E}$ on April 28, 2006 (Mala dataset not a part of the training). From the figure, it can be observed that AFRT simulations show excellent agreement with the radiative transfer simulations. The ANN is capable of predicting the brightness temperature accurately with a correlation coefficient of over $99 \%$. Furthermore, the execution of the radiative transfer simulations on an Intel Core 2 Quad $3.0 \mathrm{GHz}$ processor-based, 8 GB DDR3 RAM workstation for 12,009 test profiles took 20 hours, while the AFRT delivers the same results in just a few seconds! In summary, the AFRT can be an extremely potent tool to accomplish online retrievals.

\section{Conclusions}

Radiative transfer simulations for two tropical cyclones and for a rainfall event during the Indian southwest monsoon have been carried out using an in-house vector radiative transfer code for the MADRAS channels of microwave imager aboard the proposed Indian climate research satellite Megha-Tropiques. For purposes of validation and benchmarking, simulations have also been done for the TRMM-TMI channels. In order to work with realistic hydrometeor profiles, TMI retrieved profiles of cloud liquid water, precipitating water, cloud ice and precipitating ice are used as input for the radiative transfer simulations. The results show a reasonable agreement between the in-house code predictions and TMI measured brightness temperature for the $85 \mathrm{GHz}$ channel. Simulations are also carried out for $157 \mathrm{GHz}$ and the results show that the $157 \mathrm{GHz}$ channel is able to capture more features of the cyclone than the $85 \mathrm{GHz}$ channel. This seems to justify the choice of the high frequency $157 \mathrm{GHz}$ channel for MADRAS instrument of the Megha-Tropiques satellite. Parametric studies show that the $157 \mathrm{GHz}$ channel is more sensitive to the vertical rain/ice structure than the $85 \mathrm{GHz}$ channel and hence the former can be used to delineate scattering from rain/ice structure better, thereby raising our hopes of improved retrieval accuracies.

The need for repeated execution of radiative transfer simulation necessitates speeding up of the radiative transfer calculations. In consideration of this, for accomplishing data-driven retrievals, a neural network based fast radiative transfer model has been proposed as a substitute to the vector radiative transfer equation code, to greatly reduce the execution time for calculations. The frequencies chosen for the fast radiative transfer model again correspond to those of the MADRAS instrument. A huge database is generated from seven different rain events occurring in the North Indian region during 2000-2006. The database is split into training and testing sets. The results obtained are very encouraging and show that neural network is not only capable of predicting the brightness 
temperatures accurately with a correlation coefficient of over $99 \%$, but also does so in just a fraction of the time required by detailed numerical simulations.

\section{References}

Balaji C, Deiveegan M, Venkateshan S P, Gairola R M, Sarkar A and Agarwal V K 2009 Polarized microwave forward model simulations for tropical storm Fanoos, $J$. Earth Syst. Sci. 118(4) 331-343.

Chevallier F, Chéruy F, Scott N A and Chédin A 1998 A neural network approach for a fast and accurate computation of a longwave radiative budget; J. Appl. Meteor. 37(11) 1385-1397.

Churnside J H, Stermitz T A and Schroeder J A 1994 Temperature profiling with neural network inversion of microwave radiometer data; J. Atmos. Oceanic Technol. 11 105-109.

Czekala H 1997 Effects of ice particle shape and orientation on polarized microwave radiation for off-nadir problems; Geophys. Res. Lett. 25(10) 1669-1672.

Deirmendjian D 1969 Scattering on spherical polydispersion (New York, NY: Elsevier).

Deiveegan M 2007 Precipitation retrieval using a polarized microwave radiative transport model; Ph.D Thesis, Indian Institute of Technology Madras.

Deiveegan M, Balaji C and Venkateshan S P 2008 A polarized microwave radiative transfer model for passive microwave remote sensing; Atmos. Res. 88(3-4) $277-$ 293.

Evans K F and Stephens G L 1991 A new polarized atmospheric radiative transfer model; J. Quant. Spectrosc. Radiat. Transfer 46 413-423.

Kuligowski R J and Barros A P 2001 Combined IRmicrowave satellite retrieval of temperature and dewpoint profiles using artificial neural networks; J. Appl. Meteorol. 40 2051-2067.

Kummerow C, Barnes W, Kozu T, Shiue J and Simpson J 1998 The Tropical Rainfall Measuring Mission (TRMM) sensor package; J. Atmos. Oceanic Technol. 15 809-817.
Lei Shi 2000 Retrieval of atmospheric profiles from AMSU-A measurement using a neural network approach; J. Atmos. Oceanic Technol. 18 340-347.

Marshall J and Palmer W 1948 The distribution of raindrops with size; J. Atmos. Sci. 5(4) 165-166.

Monahan E C and O'Muircheartaigh I G 1986 Whitecaps and the passive remote sensing of the ocean surface; Int. J. Remote Sens. 5 627-642.

Pal P K, Patel V and Dutt C B S 2007 Megha-Tropiques science plan and utilisation program; Technical Report, Space Application Centre, ISRO, p. 11.

Roberti L and Kummerow C 1999 Monte Carlo calculations of polarized microwave radiation emerging from cloud structures; J. Geophys. Res. 104 2093-2104.

Schwander H, Kaifel A, Ruggaber A and Koepke P 2001 Spectral radiative-transfer modeling with minimized computation time by use of a neural-network technique; Applied Optics 40(3) 331-335.

Srinivasan J and Narayanan S 2003 The megha-tropiques mission; Proc. SPIE, doi: 10.1117/12.466703.

Tao W K and Simpson J 1993 The Goddard cumulus ensemble model. Part I: model description; Terr. Atmos. Oceanic Sci. 4 35-72.

Troitsky A V, Osharin A M, Korolev A V and Strapp J W 2003 Polarization of thermal microwave atmospheric radiation due to scattering by ice particles in clouds; $J$. Atmos. Sci. 60 1608-1620.

Tropical Rainfall Measuring Mission (TRMM) data products 2009 URL: http://mirador.gsfc.nasa.gov/cgibin/mirador/ presentNavigation.pl?tree $=$ project $\&$ project $=$ TRMM $\&$ dataGroup $=$ Orbital\&CGISESSID $=$ a 56 a45ecfd3bb175f7 95590267276551, Mirador, Goddard Earth Sciences Data And Information Services Center (last visited on February 19,2009$)$.

Ulaby F T, Moore R K and Fung A K 1981 Microwave remote sensing - active and passive (Boston: Artech House Publisher).

Wisler M M and Hollinger J P 1977 Estimation of marine environmental parameters using microwave radiometric remote sensing systems; Technical Report NRL Memo Rep. 3661, Naval Research Laboratory, Washington DC.

Zhigang Y, Hongbin C and Longfu L 2005 Retrieving atmospheric temperature profiles from AMSU-A data with neural networks; Adv. Atmos. Sci. 22 606-616. 